\title{
Increased thyroid malignancy in patients with primary hyperparathyroidism
}

\author{
Luchuan $\mathrm{Li}^{1}{ }^{1 *}$, Baoyuan $\mathrm{Li}^{2}, *$, Bin Lv ${ }^{1}$, Weili Liang ${ }^{1}$, Binbin Zhang ${ }^{1}$, Qingdong Zeng ${ }^{1}$, Andrew G Turner ${ }^{3}$ and \\ Lei Sheng(1) 1 \\ 'Department of Thyroid Surgery, General Surgery, Qilu Hospital of Shandong University, Jinan, Shandong, China \\ 2Department of Thyroid Surgery, The Affiliated Yantai Yuhuangding Hospital of Qingdao University, Yantai, Shandong, China \\ ${ }^{3} \mathrm{Clinical}$ and Health Sciences, University of South Australia, Adelaide, South Australia, Australia
}

Correspondence should be addressed to L Sheng: lei.sheng@sdu.edu.cn

$*(\mathrm{~L} L i$ and $\mathrm{B} \mathrm{Li}$ contributed equally to this work $)$

\begin{abstract}
Background: Multiple studies have reported the increased incidence of thyroid cancer in patients with primary hyperparathyroidism (PHPT). However, the underlying risk factors of concomitant thyroid cancer in patients with PHPT remain unknown. The primary aim of this study was to examine the records of patients with PHPT to identify characteristics that correlated with the presence of coexisting thyroid nodules, and which may have an implication for the prediction of thyroid cancer.

Methods: Medical records of consecutive patients with PHPT $(n=318)$ were reviewed from January 2010 to September 2020 in two tertiary medical centers in China. Patient clinicopathological and biological data were collected and analyzed.

Results: Of a total of 318 patients with PHPT, 105 (33.0\%) patients had thyroid nodules and $26(8.2 \%)$ patients were concomitant with thyroid cancer. A total of 38 thyroid nodules taken from 26 patients were pathologically assessed to be well-differentiated papillary thyroid carcinoma (PTC), with $81 \%$ being papillary thyroid microcarcinoma (PTMC). In 79\% (30/38) of these cancers, thyroid nodules were considered suspicious following preoperative ultrasound. Multinomial logistic regression analysis revealed that female gender was associated with increased risk of thyroid nodules ( $O R=2.13,95 \%$ $\mathrm{Cl}: 1.13-3.99, P=0.019)$, while lower log-transformed parathyroid hormone levels were an independent predictor of thyroid cancer in patients with PHPT (OR $=0.50,95 \% \mathrm{Cl}$ : $0.26-0.93, P=0.028$ ).

Conclusion: In conclusion, we observed a relatively high prevalence of thyroid cancer in our cohort of Chinese patients with PHPT. Evaluation of thyroid nodules by preoperative ultrasound may be advisable in patients with PHPT, particularly for females and patients with modestly elevated serum parathyroid hormone levels.
\end{abstract}

\section{Key Words}

- primary hyperparathyroidism

- thyroid malignancy

- parathyroid hormone

- surgery

\section{Introduction}

Primary hyperparathyroidism (PHPT) is a common endocrine disorder, having a prevalence of $0.04-0.1 \%$ in the general population (1). The principal role of parathyroid hormone (PTH) is to maintain (raise) blood calcium levels in three different ways: (i) release of calcium from the bones via stimulation of osteoclastic activity; (ii) decrease calcium excretion in the kidney; (iii) increase absorption of calcium from the gut (2). However persistent overproduction of PTH in patients with PHPT may damage target organs including bone and kidney, manifesting https://ec.bioscientifica.com

https://doi.org/10.1530/EC-21-0217

C 2021 The authors Published by Bioscientifica Ltd

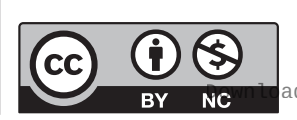

This work is licensed under a Creative Commons Attribution-NonCommercial 4.0 International License. ded from Bioscientifica.com at 04/26/2023 07:50:59AM 
as osteoporosis and kidney stones (3). A smaller number of patients may present with acute pancreatitis, gastrointestinal ulcers, or neuropsychiatric symptoms $(3,4)$. Some studies have also reported an increased risk of malignancies, including hematopoietic, breast, skin, thyroid, and urinary tract carcinoma $(5,6,7)$. Previous studies have reported $15-75 \%$ of patients with PHPT have concomitant thyroid nodules $(8,9)$. Moreover, several authors have described a rate of thyroid cancer in patients with PHPT that appears to be higher than the general population $(4,10,11,12,13,14,15)$. A review of data from nine studies, including a total of 2510 patients with PHPT requiring parathyroidectomy, indicated an incidence for thyroid cancer of 5\%, compared to international estimates ranging from $\sim 2$ to 12 per 100,000 thyroid cancer new cases per year (15). Accordingly, patients with PHPT may be at higher risk of thyroid cancer and the detection of thyroid nodules may be treated with greater suspicion. Although elusive at this time, a more detailed understanding of the risk factors contributing to this pathology would benefit clinical decision-making.

The primary aim of this retrospective study was to explore risk factors for malignancy among a cohort of 318 patients with PHPT, with or without benign or malignant thyroid nodules, presenting to two tertiary medical centers in China between 2010 and 2020 .

\section{Materials and Methods}

\section{Patients}

Clinical data were collected from patients with PHPT undergoing surgery in two large tertiary medical centers (Qilu hospital of Shandong University and the Affiliated Yantai Yuhuangding Hospital of Qingdao University) from January 2010 to September 2020. Patients with confirmed PHPT based on medical history, physical examination, and laboratory tests were eligible for inclusion. All parathyroid lesions were pathologically confirmed as either parathyroid adenoma, parathyroid carcinoma or parathyroid hyperplasia. Patients who had secondary or tertiary HPT, multiple endocrine neoplasia, a history of radiation exposure, and those with familial HPT were excluded from this study. Patients with PHPT diagnosed during the clinical work-up for thyroid nodules were also excluded. This study protocol was reviewed and approved by the Qilu Hospital and Yuhuangding Hospital Ethics Committees. Individual informed patient consent was waived due to the retrospective nature of this study.

\section{Data collection}

The data for patients with PHPT included age, gender, chronic disease history (hypertension, diabetes mellitus, and coronary heart diseases), PHPT-related comorbidity (urinary tract stones, osteoporosis, pathological fracture, pancreatitis, etc.), laboratory blood analyses within 1 week prior to surgery (PTH, calcium, 25-hydroxyvitamin D (25(OH)D), albumin, phosphorus, potassium, alkaline phosphatase (AKP), creatinine $(\mathrm{Cr})$, blood urea nitrogen (BUN), thyroid-stimulating hormone (TSH), and thyroid autoantibodies (TPOAb and $\mathrm{TgAb}$ )). The reference range of PTH was from 15 to $65 \mathrm{pg} / \mathrm{mL}$. Normality of serum calcium was from 2.11 to $2.52 \mathrm{mmol} / \mathrm{L}$. Serum calcium concentrations were adjusted for serum albumin. Adjusted calcium $=0.02(40 \mathrm{~g} / \mathrm{L}-$ serum albumin $(\mathrm{g} / \mathrm{L}))+$ measured total serum calcium $(\mathrm{mmol} / \mathrm{L})$. All patients underwent preoperative thyroid and parathyroid ultrasound imaging. Surgical options were appropriately chosen according to the 2015 American Thyroid Association guideline. Either partial, subtotal, or near-total thyroidectomy was performed for benign thyroid nodules. Where thyroid cancer was confirmed by frozen section or fine-needle aspiration biopsy (FNAB), lobectomy, near-total, or total thyroidectomy with cervical lymph node dissection was performed. Histopathological sections of parathyroid gland and thyroid nodules were reviewed by two independent pathologists. Notably, final pathological reports of thyroid cancer included the following details: tumor size, histological type, location, bilaterality, multifocality, status of extrathyroidal extension, and cervical lymph node metastasis.

\section{Statistical analysis}

Statistical analyses were performed using SPSS (version 23.0; SPSS Inc). Continuous variables were presented as mean \pm S.D. for normally distributed data or median (minimum to maximum) for non-normally distributed data except for PTH. Due to its skewed distribution, PTH was also reported as natural log-transformed values $(\mathrm{lnPTH})$ when analyzed as continuous quantities. All categorical variables were presented as proportions. Comparisons of means and proportions were performed with independent samples one-way ANOVA and the chi-square test, respectively. Nonnormally distributed variables were compared using the Mann-Whitney U-test or Kruskal-Wallis test. Multinomial logistic regression analysis was used to identify potential risk factors for thyroid nodules, including thyroid cancer and benign thyroid nodules, in patients with PHPT. Odds

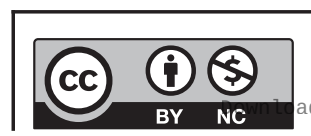

This work is licensed under a Creative Commons Attribution-NonCommercial 4.0 International License. ded from Bioscientifica.com at 04/26/2023 07:50:59AM 
ratios (OR) and the corresponding 95\% CI were calculated for risk factors. A receiver operating characteristic (ROC) analysis was performed to determine the capacity of the clinical and biochemical markers to predict thyroid malignancy in patients with PHPT. A value of $P<0.05$ was considered as statistically significant.

\section{Results}

The inclusion process of patients with PHPT was shown in Fig. 1. A total of 318 patients with PHPT were included in this study. The mean age was $53 \pm 13$ years with $70.8 \%$ $(n=225)$ of patients being female. Diagnosis with PHPT was initially based on elevated serum calcium or the presence of parathyroid nodules, primarily evident through regular health check-ups ( $n=130,41 \%)$, followed by urinary tract stones $(n=79,25 \%)$, musculoskeletal pain $(n=62,19 \%)$, nausea or vomiting $(n=30,9 \%)$, fracture $(n=11,3 \%)$, pancreatitis ( $n=3,1 \%$ ) (Fig. 2 ). The diagnosis of PHPT was always confirmed by biochemical profile, parathyroid ECT (Emission CT) and ultrasound imaging. The baseline demographic and clinical and biochemical characteristics are described in Table 1. Age was comparable between patients with thyroid cancer, benign thyroid nodules, or without thyroid nodules (Table 1$)$. Although elevated compared to the normal range (15-65 pg/mL), serum PTH levels were significantly lower in patients with thyroid cancer than patients without thyroid nodules. A larger proportion of female patients with PHPT had thyroid nodules compared to those without thyroid nodules. There were no differences observed in serum calcium, phosphorus, potassium, AKP, BUN, TSH, 25(OH)D levels, TPOAb positivity, and TgAb positivity (Table 1 ).

A histopathologic report confirmed the diagnosis in all cases with the final diagnosis of PHPT being parathyroid adenoma in 282 patients (88.68\%), atypical parathyroid adenoma in 22 patients $(6.92 \%)$, oncocytic parathyroid adenoma in 2 patients $(0.63 \%)$, parathyroid carcinoma in 8 patients $(2.52 \%)$, and parathyroid hyperplasia in 4 patients $(1.26 \%)$. Of the total of 318 patients with PHPT, $105(33.0 \%)$ patients had thyroid nodules and $26(8.2 \%)$ patients were concomitant with thyroid cancer (Table 2). Of these 26 cases, all were assessed to be well-differentiated papillary thyroid carcinoma (PTC), namely 21 cases $(81 \%)$ of papillary thyroid microcarcinoma (PTMC), 3 cases (12\%) of conventional PTC, and 2 cases (7\%) of a tall-cell variant of PTC (Table 3). Bilaterality, multifocality, extrathyroidal extension, and central lymph node metastasis were found in 7 cases (26.9\%), 8 cases (30.8\%), 8 cases (30.8\%), and 2 cases $(7.7 \%)$, respectively. Among the 26 patients, a total of 38 malignant thyroid nodules were ultimately confirmed by pathology. Prior to surgery, 30 (79\%) hypoechoic thyroid nodules were observed as suspicious by preoperative ultrasound, while 8 (21\%) thyroid nodules were neither detected nor suspicious as malignancy by ultrasound (Supplementary Table 1, see section on supplementary materials given at the end of this article).

To further investigate the factors associated with benign thyroid nodules and thyroid cancer being present

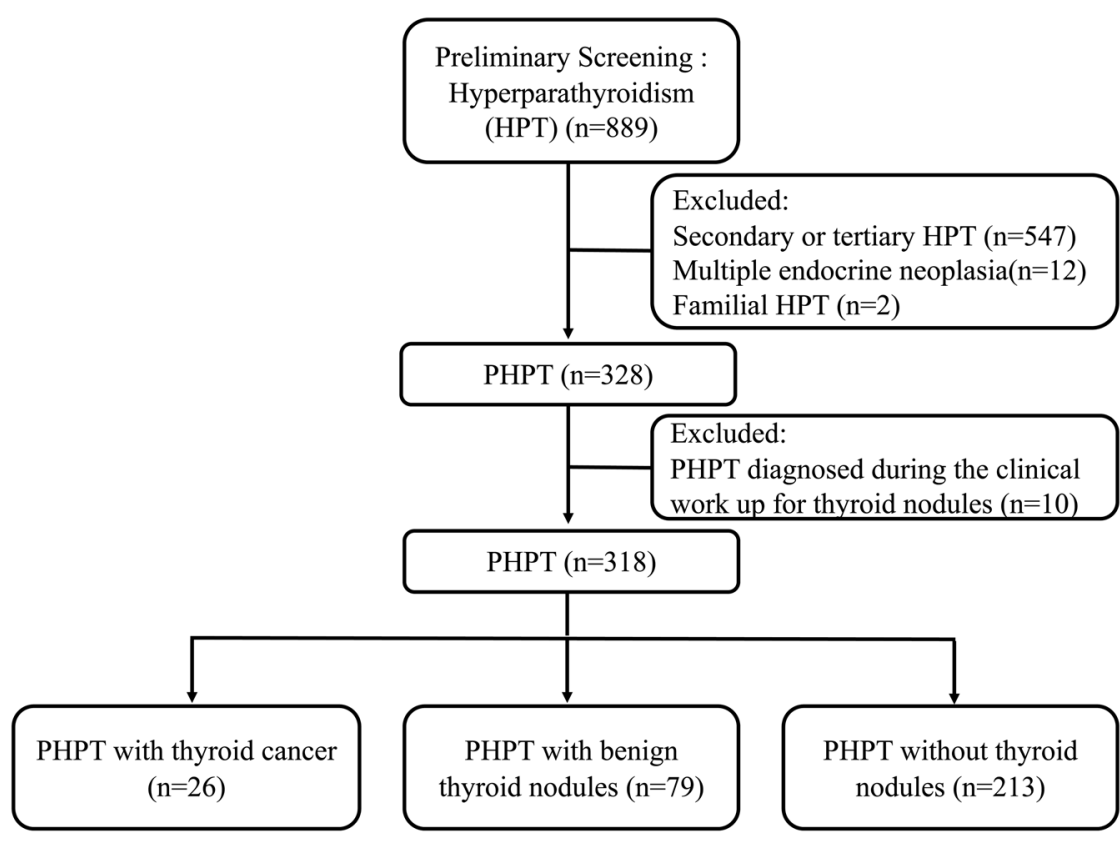

Figure 1

Criteria for including patients with primary hyperparathyroidism (PHPT). 


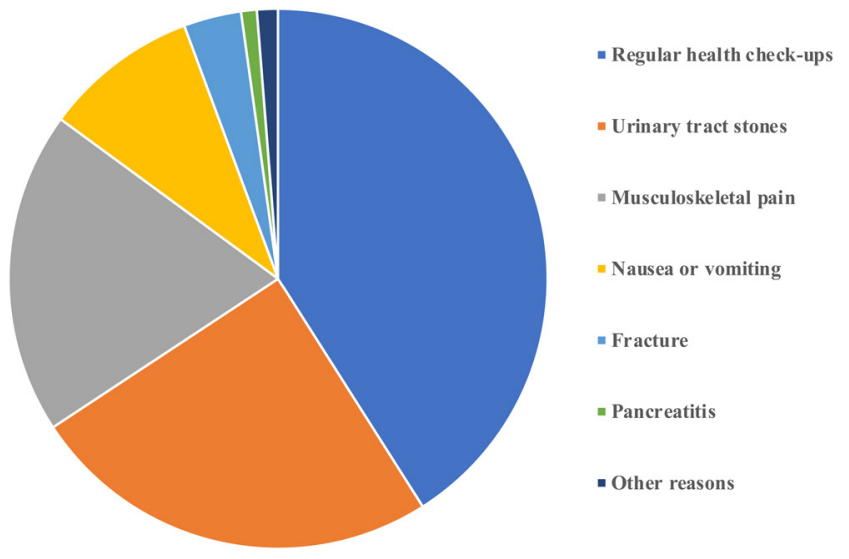

Figure 2

The clinical pattern leading to patients initially being diagnosed with PHPT. Regular health check-ups $(n=130,41 \%)$; urinary tract stones $(n=$ 79, 25\%); musculoskeletal pain ( $n=62,19 \%)$; nausea and vomiting ( $n=30$, $9 \%)$; fracture $(n=11,3 \%)$; pancreatitis $(n=3,1 \%)$; others $(n=3,1 \%)$.

in patients with PHPT, multivariate-adjusted logistic regression analyses were performed. Female gender was an independent predictor for thyroid nodules after adjusting for $\mathrm{lnPTH}$ (model 1), age, albumin-adjusted serum calcium, and creatinine (model 2). The presence of thyroid cancer was significantly associated with decreased of $\operatorname{lnPTH}(\mathrm{OR}=0.52 ; 95 \% \mathrm{CI}: 0.32-0.84 ; P=0.008)$ after adjusting for gender (model 1 ). The association remained significant after additional adjustment for age, albuminadjusted serum calcium and creatinine $(\mathrm{OR}=0.50 ; 95 \%$ CI: 0.26-0.93; $P=0.028$ ) (model 2) (Table 4). The ROC analysis revealed that serum PTH levels $<192 \mathrm{pg} / \mathrm{mL}$ had a good capacity to differentiate the thyroid malignancy from benign thyroid nodules or without thyroid nodules, with an area under the curve (AUC) of $0.687(P=0.002)$. This cutoff value for the PTH level had a sensitivity of $69.2 \%$ and a specificity of $67.8 \%$ for predicting thyroid malignancy in patients with PHPT.

\section{Discussion}

The coexistence of thyroid disease in patients with PHPT is a known clinical challenge that remains poorly understood, with highly variable incidence rates being reported and potential risk factors being unclear. The prevalence of thyroid nodules in our cohort of patients with PHPT was $33.0 \%$, being similar to other populations $(20-76 \%)(16,17)$. The proportion of female patients with PHPT having thyroid nodules was significantly higher than those without thyroid nodules and is also consistent with epidemiological findings suggesting females are more prone to developing thyroid nodules $(18,19)$. Our data did not reflect any differences in gender distribution between patients with thyroid cancer and patients with benign thyroid nodules.

To the best of our knowledge, this was the largest cohort study of thyroid cancer in patients with PHPT in China. The incidence of thyroid cancer we observed in patients with PHPT was $8.2 \%$, similar to two previous Chinese studies that have reported prevalence rates of $7.7 \%(12 / 155$ patients) and $6.3 \%$ (7/112 patients) $(12,14)$. Taken together, these three studies in Chinese populations report a higher rate of malignancy in patients with PHPT than other similar studies. Two reviews have estimated the incidence of thyroid cancer in patients with PHPT by pooling data from multiple countries, reporting average rates of 3.5\% (12) and 5\% (15). We also observed an overall rate of malignancy of $25 \%$ for thyroid nodules in patients with PHPT, which is higher than the rate reported in the general population with thyroid nodules (7-15\%) (20). Noting the highly variable nature of data in this field, these results suggest a higher rate of malignancy in our cohort compared to other similar studies, warranting some discussion of the possible contributing factors. It is striking that the average serum level of $25(\mathrm{OH}) \mathrm{D}$ we observed was $10.67 \pm 6.34 \mathrm{ng} / \mathrm{mL}(\sim 25 \mathrm{nmol} / \mathrm{L})$. Such values are not uncommon among clinical populations in China but are approximately half the commonly agreed minimum target level for vitamin D sufficiency (21). To our knowledge, vitamin D status has not been reported in other studies to allow comparison with other cohorts of patients with PHPT. Perhaps significantly, vitamin D deficiency has been increasingly implicated in the initiation and progression of numerous malignancies. However, as with other cancers, the hypothesis that vitamin D status modulates thyroid cancer incidence is equivocal (22). Nevertheless, an analysis of preoperative serum 25(OH)D levels in 548 females undergoing thyroidectomy has revealed lower $25(\mathrm{OH}) \mathrm{D}$ levels in patients with a tumor size $>1 \mathrm{~cm}(23)$.

Several studies have explored the potential role of elevated PTH and calcium levels in thyroid diseases in patients with PHPT but have reported conflicting results (3, 14). One previous study involving a total of 59 PHPT cases indicated that high PTH levels were significantly associated with the development of thyroid cancer (3), while another two studies found no correlation between thyroid cancer and serum PTH levels $(14,24)$. In contrast, we have observed in our relatively large patient cohort that preoperative serum PTH levels were significantly lower in patients with thyroid cancer than in patients without thyroid nodules. Furthermore, a low value for log-transformed PTH was found to be an independent predictor for the presence

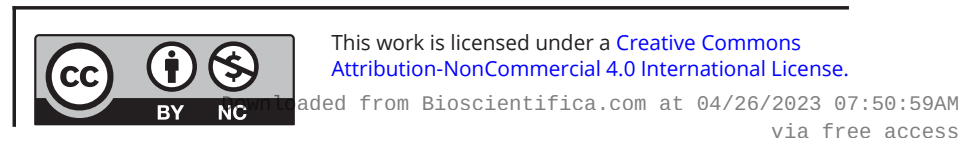


Table 1 Clinical and biologic characteristics between PHTP with and without benign or malignant thyroid nodules.

\begin{tabular}{|c|c|c|c|c|}
\hline & Total PHPT $(n=318)$ & $\begin{array}{l}\text { Thyroid carcinoma } \\
\qquad(n=26)\end{array}$ & $\begin{array}{l}\text { Benign thyoid nodule } \\
\qquad(n=79)\end{array}$ & $\begin{array}{l}\text { Without thyroid } \\
\text { nodules }(n=213)\end{array}$ \\
\hline Age & $53 \pm 13$ & $53 \pm 7$ & $56 \pm 10^{a}$ & $52 \pm 14$ \\
\hline \multicolumn{5}{|l|}{ Sex } \\
\hline Male & $93(29.2 \%)$ & $4(15.4 \%)$ & $15(19.0 \%)$ & $74(34.7 \%)$ \\
\hline Female & $225(70.8 \%)$ & $22(84.6 \%)^{a}$ & $64(81.0 \%)^{b}$ & 139 (65.3\%) \\
\hline \multicolumn{5}{|l|}{ Comorbidity } \\
\hline Hypertension & $85(26.7 \%)$ & $7(26.9 \%)$ & $21(26.6 \%)$ & $57(26.8 \%)$ \\
\hline Diabetes mellitus & $27(8.5 \%)$ & $1(3.8 \%)$ & $7(8.9 \%)$ & $19(8.9 \%)$ \\
\hline Coronary heart diease & $22(6.9 \%)$ & $1(3.8 \%)$ & $6(7.6 \%)$ & $15(7.0 \%)$ \\
\hline Urinary tract stones & $99(31.1 \%)$ & $4(15.4 \%)^{a}$ & $14(17.7 \%)^{b}$ & $81(38.0 \%)$ \\
\hline Osteoporosis & $60(18.9 \%)$ & $4(15.4 \%)$ & $21(26.6 \%)$ & $35(16.4 \%)$ \\
\hline Pathological fracture & $11(3.5 \%)$ & $1(3.8 \%)$ & $1(1.3 \%)$ & $9(4.2 \%)$ \\
\hline Pancreatitis & $3(0.9 \%)$ & $0(0.0 \%)$ & $2(2.5 \%)$ & $1(0.5 \%)$ \\
\hline Malignant tumor history & $10(3.1 \%)$ & $1(3.8 \%)$ & $4(5.1 \%)$ & $5(2.3 \%)$ \\
\hline Gastrointestinal ulcer & $1(0.3 \%)$ & $0(0.0 \%)$ & $0(0.0 \%)$ & $1(0.5 \%)$ \\
\hline \multicolumn{5}{|l|}{ Biological features } \\
\hline PTH (pg/mL) & $284.9(30.63-5000.0)$ & $143.85(30.6-3576.0)^{b}$ & $275.3(73.15-3545.0)$ & $336.0(65.8-5000.0)$ \\
\hline $\mathrm{InPTH}$ & $5.88 \pm 1.05$ & $5.34 \pm 1.19^{b}$ & $5.81 \pm 0.95$ & $5.97 \pm 1.04$ \\
\hline Serum calcium (mmol/L) & $3.02 \pm 0.48$ & $2.93 \pm 0.45$ & $2.95 \pm 0.49$ & $3.06 \pm 0.47$ \\
\hline $\begin{array}{l}\text { Adjusted serum calcium } \\
(\mathrm{mmol} / \mathrm{L})\end{array}$ & $2.97 \pm 0.50$ & $2.86 \pm 0.47$ & $2.90 \pm 0.50$ & $3.01 \pm 0.49$ \\
\hline Serum phosphorus (mmol/L) & $0.79 \pm 0.24$ & $0.81 \pm 0.17$ & $0.82 \pm 0.31$ & $0.77 \pm 0.21$ \\
\hline Serum potassium (mmol/L) & $4.11 \pm 0.49$ & $4.10 \pm 0.46$ & $4.14 \pm 0.50$ & $4.10 \pm 0.49$ \\
\hline AKP $(U / L)$ & $125(22-2540)$ & $99(56-734)$ & $119(53-1447)$ & $136(22-2540)$ \\
\hline $\mathrm{Cr}(\mu \mathrm{mol} / \mathrm{L})$ & $69.36 \pm 36.41$ & $65.22 \pm 22.70$ & $61.87 \pm 31.19^{a}$ & $72.65 \pm 39.10$ \\
\hline BUN (mmol/L) & $5.05 \pm 2.50$ & $4.44 \pm 1.55$ & $4.81 \pm 2.61$ & $5.21 \pm 2.54$ \\
\hline $\mathrm{TSH}(\mu \mathrm{IU} / \mathrm{mL})$ & $1.66(0.003-25.59)$ & $2.21(0.003-4.43)$ & $1.87(0.006-6.33)$ & $1.50(0.05-25.59)$ \\
\hline $25(\mathrm{OH}) \mathrm{D}(\mathrm{ng} / \mathrm{mL})^{\mathrm{c}}$ & $10.67 \pm 6.34(135)$ & $12.46 \pm 7.28(14)$ & $10.25 \pm 5.65(28)$ & $10.53 \pm 6.42(93)$ \\
\hline TPOAb positivityc & $26.6 \%(53 / 199)$ & $25.0 \%(5 / 20)$ & $28.1 \%(16 / 57)$ & $26.2 \%(32 / 122)$ \\
\hline TgAb positivityc & $32.5 \%(63 / 194)$ & $35.0 \%(7 / 20)$ & $31.6 \%(18 / 57)$ & $32.5 \%(38 / 117)$ \\
\hline
\end{tabular}

a $P$ value $<0.05$ as compared to patients with PHPT without thyroid nodules; ${ }^{b} P$ value $<0.01$ as compared to patients with PHPT without thyroid nodules; 'Data were available in a smaller cohort and number of cases with available data are listed in brackets.

25(OH)D, 25-hydroxyvitamin D; AKP, alkaline phosphatase; IBUN, blood urea nitrogen; Cr, creatinine; In, natural logarithm; PHPT, primary

hyperparathyroidism; PTH, parathyroid hormone; TgAb, thyroglobulin antibody; TPOAb, thyroid peroxidase antibody; TSH, thyroid-stimulating hormone.

of thyroid cancer in patients with PHPT after adjusting for other confounding factors. A possible correlation between serum calcium levels and various cancers in the general population, such as colorectal and breast, remains controversial $(25,26,27)$. One study from a Chinese group found a significant negative correlation between the albumin-corrected serum calcium level and the presence of thyroid cancer in patients with PHPT (14). Our data suggest adjusted serum calcium levels may belower in PHPT patients with thyroid cancer, although no statistical difference was observed compared to patients with benign nodules, or without nodules $(P=0.129)$. A small cross-sectional study consisting of 40 medullary thyroid cancer patients and 40 healthy controls showed a low serum calcium level was a potent risk factor for medullary thyroid cancer (28). And a case-control study including 1092 participants, indicated that lower serum calcium levels were an independent predictor of thyroid nodules among patients with type 2

Table 2 Association of benign and malignant thyroid nodules with PHTP.

\begin{tabular}{|c|c|c|c|c|}
\hline & \multirow[b]{2}{*}{ Total $(n=318)(\%)$} & Not concomitant with thyroid nodules & \multicolumn{2}{|c|}{ Concomitant with thyroid nodules } \\
\hline & & $(n=213)(\%)$ & Benign $(n=79)(\%)$ & Malignant $(n=26)(\%)$ \\
\hline Parathyroid adenoma & $282(88.68)$ & $184(86.38)$ & $72(91.14)$ & $26(100)$ \\
\hline $\begin{array}{l}\text { Atypical parathyroid } \\
\text { adenoma }\end{array}$ & $22(6.92)$ & $19(8.92)$ & $3(3.80)$ & $0(0)$ \\
\hline $\begin{array}{l}\text { Oncocytic parathyroid } \\
\text { adenoma }\end{array}$ & $2(0.63)$ & $2(0.94)$ & $0(0)$ & $0(0)$ \\
\hline Parathyroid carcinoma & $8(2.52)$ & $7(3.29)$ & $1(1.27)$ & $0(0)$ \\
\hline Parathyroid hyperplasia & $4(1.26)$ & $1(0.47)$ & $3(3.80)$ & $0(0)$ \\
\hline $\begin{array}{l}\text { https://ec.bioscientifica.com } \\
\text { https://doi.org/10.1530/EC-21-0217 }\end{array}$ & Publish & $\begin{array}{l}\text { () } 2021 \text { The authors } \\
\text { by Bioscientifica Ltd }\end{array}$ & $\begin{array}{l}\text { This work is license } \\
\text { Attribution-NonCon }\end{array}$ & $\begin{array}{l}\text { ler a Creative Commons } \\
\text { cial } 4.0 \text { International License. }\end{array}$ \\
\hline
\end{tabular}


Table 3 Characteristics of patients with PHPT and thyroid carcinoma.

\begin{tabular}{|c|c|c|c|c|c|}
\hline Case & Age & Sex & $\begin{array}{l}\text { Location } \\
\text { of tumor }\end{array}$ & $\begin{array}{l}\text { Number } \\
\text { of tumor }\end{array}$ & Tumor type \\
\hline 1 & 53 & Female & Left & 2 & PTMC \\
\hline 2 & 55 & Female & Left & 1 & Conventional PTC \\
\hline 3 & 63 & Male & Right & 1 & PTMC \\
\hline 4 & 43 & Female & Left & 1 & PTMC \\
\hline 5 & 54 & Female & Bilateral & 2 & PTMC \\
\hline 6 & 57 & Female & Right & 1 & PTMC \\
\hline 7 & 44 & Male & Left & 1 & PTMC \\
\hline 8 & 52 & Male & Left & 1 & PTMC \\
\hline 9 & 45 & Female & Bilateral & 2 & Conventional PTC \\
\hline 10 & 63 & Female & Bilateral & 2 & PTMC \\
\hline 11 & 58 & Female & Bilateral & 3 & PTMC \\
\hline 12 & 41 & Female & Right & 1 & PTMC \\
\hline 13 & 54 & Male & Left & 1 & PTMC \\
\hline 14 & 66 & Female & Right & 1 & PTMC \\
\hline 15 & 54 & Female & Left & 1 & Conventional PTC \\
\hline 16 & 43 & Female & Right & 1 & PTMC \\
\hline 17 & 47 & Female & Bilateral & 4 & Tall-cell variant of PTC \\
\hline 18 & 67 & Female & Right & 1 & Tall-cell variant of PTC \\
\hline 19 & 52 & Female & Bilateral & 3 & PTMC \\
\hline 20 & 52 & Female & Right & 1 & PTMC \\
\hline 21 & 57 & Female & Left & 1 & PTMC \\
\hline 22 & 60 & Female & Right & 1 & PTMC \\
\hline 23 & 52 & Female & Left & 1 & PTMC \\
\hline 24 & 59 & Female & Left & 1 & PTMC \\
\hline 25 & 46 & Female & Bilateral & 2 & PTMC \\
\hline 26 & 46 & Female & Left & 1 & PTMC \\
\hline
\end{tabular}

\begin{tabular}{c}
\hline Tumor size $(\mathrm{cm})$ \\
\hline $0.4,0.1$ \\
1.1 \\
0.4 \\
0.8 \\
$0.5,0.6$ \\
1 \\
0.7 \\
0.5 \\
$0.6,1.5$ \\
$0.1,0.4$ \\
$1.0,0.7,0.6$ \\
0.3 \\
1 \\
0.9 \\
1.1 \\
0.4 \\
$0.5,0.3,0.06$ \\
1.3 \\
$0.6,0.3,0.3$ \\
0.5 \\
0.4 \\
0.6 \\
0.5 \\
0.5 \\
$0.4,0.3$ \\
0.7 \\
\hline
\end{tabular}

\begin{tabular}{|c|c|}
\hline $\begin{array}{c}\text { PTH } \\
(\mathrm{pg} / \mathrm{mL})\end{array}$ & $\begin{array}{l}\text { Extrathyroidal } \\
\text { extension }\end{array}$ \\
\hline 1813.0 & No \\
\hline 77.1 & Yes \\
\hline 321.3 & Yes \\
\hline 1039.0 & No \\
\hline 66.1 & No \\
\hline 111.9 & No \\
\hline 3576.0 & No \\
\hline 396.5 & No \\
\hline 115.8 & Yes \\
\hline 159.2 & No \\
\hline 190.6 & No \\
\hline 1548.0 & No \\
\hline 1430.0 & No \\
\hline 149.9 & Yes \\
\hline 103.8 & Yes \\
\hline 30.6 & No \\
\hline 171.2 & Yes \\
\hline 85.3 & Yes \\
\hline 128.3 & Yes \\
\hline 373.2 & No \\
\hline 80.7 & No \\
\hline 146.5 & No \\
\hline 141.2 & No \\
\hline 98.2 & No \\
\hline 103.6 & No \\
\hline 100.4 & No \\
\hline
\end{tabular}

\begin{tabular}{l} 
Central lymph \\
node metastasis \\
\hline No $(0 / 5)$ \\
No $(0 / 10)$ \\
No $(0 / 3)$ \\
No $(0 / 6)$ \\
Yes $(2 / 10)$ \\
No $(0 / 2)$ \\
No $(0 / 2)$ \\
No $(0 / 6)$ \\
Yes $(6 / 12)$ \\
No $(0 / 4)$ \\
NA \\
NA \\
NA \\
No $(0 / 9)$ \\
No $(0 / 15)$ \\
NA \\
No $(0 / 10)$ \\
No $(0 / 1)$ \\
No $(0 / 11)$ \\
No $(0 / 3)$ \\
No $(0 / 1)$ \\
No (0/6) \\
No (0/6) \\
No (0/4) \\
No (0/2) \\
No (0/2) \\
\hline
\end{tabular}

ETE, extrathyroidal extension; NA, not available; PHPT, primary hyperparathyroidism; PTC, papillary thyroid cancer; PTMC, papillary thyroid microcarcinoma.

diabetes mellitus (adjusted OR $=1.98$, 95\% CI 1.66-2.84) (29). Collectively, the association between serum calcium or PTH levels and the presence of thyroid cancer in patients with PHPT remains unclear, requiring further studies with a larger sample size.

The rate of multifocality of thyroid cancer was three times as high (7 out of 18) in PHPT patients with relatively lower PTH levels $(<192 \mathrm{pg} / \mathrm{mL})$ than patients with higher PTH levels ( 1 out of 8$)(>192 \mathrm{pg} / \mathrm{mL}$ ) (Table 3$)$. Furthermore, 4 cases with thyroid cancers larger than $1 \mathrm{~cm}$ exclusively belonged to patients with PTH levels $<192 \mathrm{pg} / \mathrm{mL}$, which is consistent with a previous study suggesting tumor size was larger in PHPT patients with lower preoperative PTH levels than in secondary hyperparathyroidism with higher PTH levels (30). One hypothesis for this observation is that hyperparathyroidism with modestly elevated PTH levels is more likely to be asymptomatic, thus extending the occult period and prolonging the exposure of thyroid cells to a microenvironment that stimulates transformation to malignancy. However, the underlying mechanism warrants further investigation.
Molecular analyses indicate that mitogen-activated protein kinase (MAPK) pathway activation is crucial for the initiation of PTC, particularly in patients with BRAF V600E mutation or RET/PTC rearrangements (31). In addition, the Wnt/ $\beta$-catenin signaling pathway plays a critical role in driving the development and progression of PTC by promoting cell proliferation and invasion $(32,33)$. Previous studies have indicated that PTH exerts antiapoptotic or proliferating actions by activating Wnt/ $\beta$-catenin or MAPK signaling pathways in osteoblastic cells, demonstrating its mitogenic effects $(34,35)$. We hypothesize that PTH may potentiate the intrinsic MAPK signaling pathway in patients harboring BRAF V6OOE mutation or RET/PTC rearrangements. Unfortunately, genetic profiles of patients with PTC included in our study were unavailable.

Currently, there are no guidelines to manage the coexistence of thyroid nodules in patients with PHPT. For thyroid cancer, lobectomy or total thyroidectomy with cervical lymph node dissection is recommended according to 2015 ATA (American Thyroid Association) guidelines (20). For PHPT, the surgical approach has transitioned from bilateral 
Table 4 Risk of thyroid nodules, benign thyroid nodules, and thyroid cancer by serum PTH.

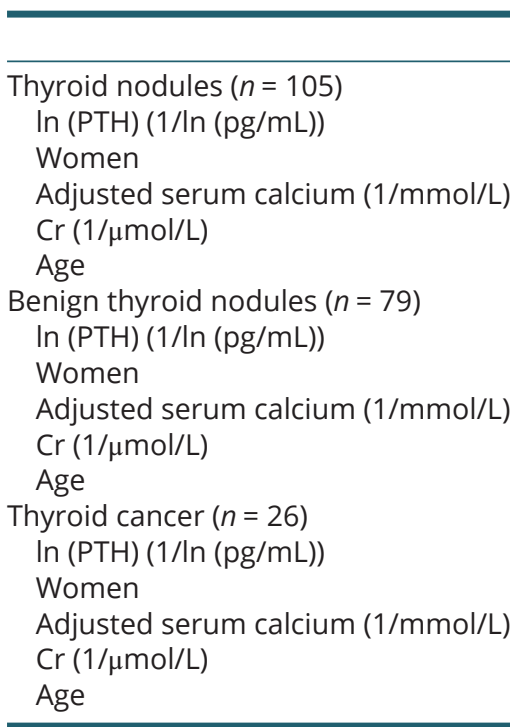

\begin{tabular}{c}
\hline Model 1, OR $(95 \% \mathrm{Cl})$ \\
\hline $0.79(0.62-1.00)$ \\
$2.39(1.33-4.30)$ \\
- \\
- \\
- \\
$0.88(0.68-1.15)$ \\
$2.31(1.21-4.43)$ \\
- \\
- \\
- \\
$0.52(0.32-0.84)$ \\
$2.66(0.87-8.09)$ \\
- \\
- \\
-
\end{tabular}

\begin{tabular}{c}
\hline P value \\
\hline 0.052 \\
0.004 \\
- \\
- \\
- \\
0.354 \\
0.011 \\
- \\
- \\
- \\
0.008 \\
0.086 \\
- \\
- \\
-
\end{tabular}

\begin{tabular}{c}
\hline Model 2, OR $(95 \% \mathrm{Cl})$ \\
\hline $0.88(0.65-1.20)$ \\
$2.13(1.13-3.99)$ \\
$0.83(0.41-1.68)$ \\
$1.00(0.99-1.01)$ \\
$1.02(0.99-1.04)$ \\
$1.04(0.75-1.44)$ \\
$1.98(0.98-3.98)$ \\
$0.76(0.35-1.66)$ \\
$0.99(0.98-1.00)$ \\
$1.03(1.00-1.05)$ \\
$0.50(0.26-0.93)$ \\
$2.69(0.83-8.75)$ \\
$1.25(0.35-4.50)$ \\
$1.00(0.99-1.02)$ \\
$1.00(0.96-1.03)$
\end{tabular}

P value

0.884

0.019

0.609

0.222

0.102

0.835

0.056

0.490

0.132

0.038

0.028

0.100

0.734

0.855

0.834

Multinomial adjusted logistic regression analyses for 318 patients with PHPT. Patients with primary hyperparathyroidism without thyroid nodules were used as a reference group. Model 1 is adjusted for gender. Model 2 is further adjusted for age, creatinine (Cr), and albumin-adjusted serum calcium.

In, natural logarithm; PTH, parathyroid hormone.

neck exploration to minimally invasive parathyroidectomy (10). However, it should be cautioned that this minimally invasive approach may lead to concomitant thyroid disease being missed. In agreement with previous reports $(14,24$, $30), 22$ out of 26 cases (84.6\%) we observed were TMC and rarely involved any local lymph node or distant metastasis. Thyroid cancer in 19 out of 26 cases (73\%) was confined to a single lobe, thus lobectomy and not total thyroidectomy should be recommended for low-risk thyroid cancer to minimize surgery-associated complications $(36,37)$. Due to the indolent nature of PTMC, active surveillance instead of immediate surgical intervention may be an alternative feasible option for low-risk PTMCs $(38,39)$. Our observation was that a small proportion of malignant thyroid nodules were undetected or neglected by preoperative ultrasound, but identified through intraoperative exploration. However, it is of note that a large proportion of thyroid nodules that were suspicious by preoperative ultrasound were pathologically confirmed as thyroid cancer. Thus, evaluation of thyroid diseases by preoperative ultrasound and FNAB for larger thyroid nodules should be recommended in patients with PHPT.

A limitation of this study was that serum PTH and calcium levels were measured at a single point within 1 week prior to surgery, and these data may have varied at other time points. Although the low serum $25(\mathrm{OH})$ D levels measured in a subset of patients are intriguing, these data were not sufficient to test for an association between vitamin $\mathrm{D}$ deficiency and risk of malignancy.
Moreover, a small set of patients with asymptomatic PHPT not undergoing surgery were excluded from our analysis, leading to a potential selection bias.

\section{Conclusions}

Both benign and malignant thyroid nodules may be commonly encountered in patients with primary hyperparathyroidism. We have observed a relatively high prevalence of thyroid malignancy in our cohort of Chinese patients with PHPT. Our analyses suggest that evaluation of thyroid nodules by preoperative ultrasound is warranted in patients with PHPT, particularly for female patients and those with modestly elevated serum parathyroid hormone levels.

\section{Supplementary materials}

This is linked to the online version of the paper at https://doi.org/10.1530/ EC-21-0217.

\section{Declaration of interest}

The authors declare that there is no conflict of interest that could be perceived as prejudicing the impartiality of the research reported.

\section{Funding}

This work was supported by the National Natural Science Foundation of China (Grant No. 81802642; Grant recipient: Lei Sheng) and Shandong Provincial Natural Science Foundation of China (Grant No. ZR2019PH082; Grant recipient: Weili Liang).

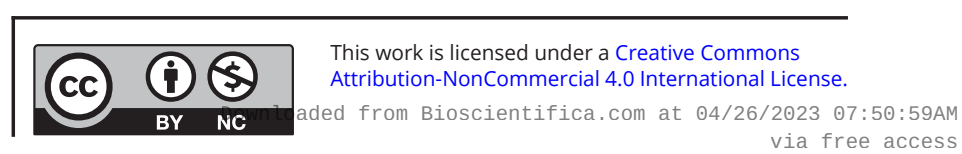




\section{Ethics approval}

This study protocol was reviewed and approved by the Qilu Hospital and Yuhuangding Hospital Ethics Committees. Individual informed patient consent was waived due to the retrospective nature of this study.

\section{Author contribution statement}

$L L, B L$, and $L S$ designed the study. $B L, W L, Q Z$, and $B Z$ collected the data and performed the analyses. All authors discussed the results, wrote and approved the submission of the manuscript.

\section{References}

1 Çetin K, Sıkar HE, Temizkan Ş, Ofluoğlu CB, Özderya A, Aydın K, Gül AE \& Küçük HF. Does primary hyperparathyroidism have an association with thyroid papillary cancer? A retrospective cohort study. World Journal of Surgery 201943 1243-1248. (https://doi. org/10.1007/s00268-019-04920-4)

2 Khundmiri SJ, Murray RD \& Lederer E. PTH and vitamin D. Comprehensive Physiology 20166 561-601. (https://doi.org/10.1002/ cphy.c140071)

3 Vargas-Ortega G, Balcazar-Hernandez L, Gonzalez-Virla B, Ramirez-Renteria C, Nieto-Guzman O, Garrido-Mendoza AP, Flores-Maya MA, Mercado M \& Victoria MZ. Symptomatic primary hyperparathyroidism as a risk factor for differentiated thyroid cancer. Journal of Thyroid Research 20182018 9461079. (https://doi. org/10.1155/2018/9461079)

4 Lehwald N, Cupisti K, Krausch M, Ahrazoglu M, Raffel A \& Knoefel WT. Coincidence of primary hyperparathyroidism and nonmedullary thyroid carcinoma. Hormone and Metabolic Research 201345 660-663. (https://doi.org/10.1055/s-0033-1345184)

5 Pickard AL, Gridley G, Mellemkjae L, Johansen C, KofoedEnevoldsen A, Cantor KP \& Brinton LA. Hyperparathyroidism and subsequent cancer risk in Denmark. Cancer 200295 1611-1617. (https://doi.org/10.1002/cncr.10846)

6 Nilsson IL, Zedenius J, Yin L \& Ekbom A. The association between primary hyperparathyroidism and malignancy: nationwide cohort analysis on cancer incidence after parathyroidectomy. EndocrineRelated Cancer 200714 135-140. (https://doi.org/10.1677/erc.1.01261)

7 Palmieri S, Roggero L, Cairoli E, Morelli V, Scillitani A, Chiodini I \& Eller-Vainicher C. Occurrence of malignant neoplasia in patients with primary hyperparathyroidism. European Journal of Internal Medicine 201743 77-82. (https://doi.org/10.1016/j.ejim.2017.06.001)

8 Morita SY, Somervell H, Umbricht CB, Dackiw AP \& Zeiger MA. Evaluation for concomitant thyroid nodules and primary hyperparathyroidism in patients undergoing parathyroidectomy or thyroidectomy. Surgery $2008 \mathbf{1 4 4}$ 862-866; discussion 866-868. (https://doi.org/10.1016/j.surg.2008.07.029)

9 Arciero CA, Shiue ZS, Gates JD, Peoples GE, Dackiw AP, Tufano RP, Libutti SK, Zeiger MA \& Stojadinovic A. Preoperative thyroid ultrasound is indicated in patients undergoing parathyroidectomy for primary hyperparathyroidism. Journal of Cancer 20123 1-6. (https:// doi.org/10.7150/jca.3.1)

10 Kosem M, Algun E, Kotan C, Harman M \& Ozturk M. Coexistent thyroid pathologies and high rate of papillary cancer in patients with primary hyperparathyroidism: controversies about minimal invasive parathyroid surgery. Acta Chirurgica Belgica 2004104 568-571. (https://doi.org/10.1080/00015458.2004.11679616)

11 Ogburn PL \& Black BM. Primary hyperparathyroidism and papillary adenocarcinoma of the thyroid; report of four cases. Proceedings of the Staff Meetings: Mayo Clinic 195631 295-298.

12 Shen J, Wu Q \& Wang Y. The role of ultrasound in the diagnosis of the coexistence of primary hyperparathyroidism and non-medullary thyroid carcinoma. BMC Medical Imaging 201919 7. (https://doi. org/10.1186/s12880-019-0306-8)

13 Linos DA, van Heerden JA \& Edis AJ. Primary hyperparathyroidism and nonmedullary thyroid cancer. American Journal of Surgery 1982 143 301-303. (https://doi.org/10.1016/0002-9610(82)90095-2)

14 Xue Y, Ye ZQ, Zhou HW, Shi BM, Yi XH \& Zhang KQ. Serum calcium and risk of nonmedullary thyroid cancer in patients with primary hyperparathyroidism. Medical Science Monitor 201622 4482-4489. (https://doi.org/10.12659/msm.898138)

15 Cinamon U, Levy D \& Marom T. Is primary hyperparathyroidism a risk factor for papillary thyroid cancer? An exemplar study and literature review. International Archives of Otorhinolaryngology 2015 19 42-45. (https://doi.org/10.1055/s-0034-1396520)

16 Dean DS \& Gharib H. Epidemiology of thyroid nodules. Best Practice and Research: Clinical Endocrinology and Metabolism 200822 901-911. (https://doi.org/10.1016/j.beem.2008.09.019)

17 Vanderpump MP. The epidemiology of thyroid disease. British Medical Bulletin 201199 39-51. (https://doi.org/10.1093/bmb/ldr030)

18 Yan HX, Pang P, Wang FL, Tian W, Luo YK, Huang W, Yang GQ, Jin N, Zang L, Du J, et al. Dynamic profile of differentiated thyroid cancer in male and female patients with thyroidectomy during 2000-2013 in China: a retrospective study. Scientific Reports 20177 15832. (https:// doi.org/10.1038/s41598-017-14963-z)

19 Rahbari R, Zhang L \& Kebebew E. Thyroid cancer gender disparity. Future Oncology 20106 1771-1779. (https://doi.org/10.2217/fon.10.127)

20 Haugen BR, Alexander EK, Bible KC, Doherty GM, Mandel SJ, Nikiforov YE, Pacini F, Randolph GW, Sawka AM, Schlumberger M, et al. 2015 American Thyroid Association management guidelines for adult patients with thyroid nodules and differentiated thyroid cancer: the American Thyroid Association guidelines task force on thyroid nodules and differentiated thyroid cancer. Thyroid 201626 1-133. (https://doi.org/10.1089/thy.2015.0020)

21 Kimball SM \& Holick MF. Official recommendations for vitamin D through the life stages in developed countries. European Journal of Clinical Nutrition 202074 1514-1518. (https://doi.org/10.1038/s41430020-00706-3)

22 Zhao J, Wang H, Zhang Z, Zhou X, Yao J, Zhang R, Liao L \& Dong J. Vitamin D deficiency as a risk factor for thyroid cancer: a metaanalysis of case-control studies. Nutrition 201957 5-11. (https://doi. org/10.1016/j.nut.2018.04.015)

23 Kim JR, Kim BH, Kim SM, Oh MY, Kim WJ, Jeon YK, Kim SS, Lee BJ, Kim YK \& Kim IJ. Low serum 25 hydroxyvitamin D is associated with poor clinicopathologic characteristics in female patients with papillary thyroid cancer. Thyroid 201424 1618-1624. (https://doi. org/10.1089/thy.2014.0090)

24 Kutlutürk K, Otan E, Yağcı MA, Usta S, Aydın C \& Ünal B. Thyroid pathologies accompanying primary hyperparathyroidism: a high rate of papillary thyroid microcarcinoma. Ulusal Cerrahi Dergisi 201430 125-128. (https://doi.org/10.5152/UCD.2014.2685)

25 Fuszek P, Lakatos P, Tabak A, Papp J, Nagy Z, Takacs I, Horvath HC, Lakatos PL \& Speer G. Relationship between serum calcium and CA 19-9 levels in colorectal cancer. World Journal of Gastroenterology 2004 10 1890-1892. (https://doi.org/10.3748/wjg.v10.i13.1890)

26 Almquist M, Manjer J, Bondeson L \& Bondeson AG. Serum calcium and breast cancer risk: results from a prospective cohort study of 7,847 women. Cancer Causes and Control 200718 595-602. (https://doi. org/10.1007/s10552-007-9001-0)

27 Wulaningsih W, Michaelsson K, Garmo H, Hammar N, Jungner I, Walldius G, Lambe M, Holmberg L \& Van Hemelrijck M. Serum calcium and risk of gastrointestinal cancer in the Swedish AMORIS study. BMC Public Health 201313 663. (https://doi.org/10.1186/14712458-13-663)

28 Emami A, Nazem MR, Shekarriz R \& Hedayati M. Micronutrient status (calcium, zinc, vitamins D and E) in patients with medullary thyroid carcinoma: a cross-sectional study. Nutrition 201741 86-89. (https:// doi.org/10.1016/j.nut.2017.04.004) 
29 Bener A, Ozdenkaya Y, Al-Hamaq AOAA, Barisik CC \& Ozturk M. Low vitamin D deficiency associated with thyroid disease among type 2 diabetic mellitus patients. Journal of Clinical Medicine Research 201810 707-714. (https://doi.org/10.14740/jocmr3507w)

30 Preda C, Branisteanu D, Armasu I, Danila R, Velicescu C, Ciobanu D, Covic A \& Grigorovici A. Coexistent papillary thyroid carcinoma diagnosed in surgically treated patients for primary versus secondary hyperparathyroidism: same incidence, different characteristics. BMC Surgery 201919 94. (https://doi.org/10.1186/s12893-019-0556-y)

31 Nikiforov YE \& Nikiforova MN. Molecular Genetics and diagnosis of thyroid cancer. Nature Reviews: Endocrinology 20117 569-580. (https:// doi.org/10.1038/nrendo.2011.142)

32 Zhang J, Gill AJM, Issacs JD, Atmore B, Johns A, Delbridge LW, Lai R $\&$ McMullen TPW. The Wnt/ $\beta$-catenin pathway drives increased cyclin D1 levels in lymph node metastasis in papillary thyroid cancer. Human Pathology 201243 1044-1050. (https://doi.org/10.1016/j. humpath.2011.08.013)

33 Pang R, Xu Y, Hu X, Liu B \& Yu J. Vitamin D receptor knockdown attenuates the antiproliferative, pro-apoptotic and anti-invasive effect of vitamin D by activating the Wnt/ $\beta$-catenin signaling pathway in papillary thyroid cancer. Molecular Medicine Reports 202022 4135-4142. (https://doi.org/10.3892/mmr.2020.11522)

34 Tobimatsu T, Kaji H, Sowa H, Naito J, Canaff L, Hendy GN, Sugimoto T \& Chihara K. Parathyroid hormone increases beta-catenin levels through Smad3 in mouse osteoblastic cells. Endocrinology 2006147 2583-2590. (https://doi.org/10.1210/en.2005-1627)
35 Swarthout JT, Doggett TA, Lemker JL \& Partridge NC. Stimulation of extracellular signal-regulated kinases and proliferation in rat osteoblastic cells by parathyroid hormone is protein kinase C-dependent. Journal of Biological Chemistry 2001276 7586-7592. (https://doi.org/10.1074/jbc.M007400200)

36 Chan S, Karamali K, Kolodziejczyk A, Oikonomou G, Watkinson J, Paleri V, Nixon I \& Kim D. Systematic review of recurrence rate after hemithyroidectomy for low-risk well-differentiated thyroid cancer. European Thyroid Journal 20209 73-84. (https://doi. org/10.1159/000504961)

37 Song E, Han M, Oh HS, Kim WW, Jeon MJ, Lee YM, Kim TY, Chung KW, Kim WB, Shong YK, et al. Lobectomy is feasible for 1-4 cm papillary thyroid carcinomas: a 10-year propensity score matchedpair analysis on recurrence. Thyroid 201929 64-70. (https://doi. org/10.1089/thy.2018.0554)

38 Kwon H, Oh HS, Kim M, Park S, Jeon MJ, Kim WG, Kim WB, Shong YK, Song DE, Baek JH, et al. Active surveillance for patients with papillary thyroid microcarcinoma: a single center's experience in Korea. Journal of Clinical Endocrinology and Metabolism 2017102 1917-1925. (https:// doi.org/10.1210/jc.2016-4026)

39 Molinaro E, Campopiano MC, Pieruzzi L, Matrone A, Agate L, Bottici V, Viola D, Cappagli V, Valerio L, Giani C, et al. Active surveillance in papillary thyroid microcarcinomas is feasible and safe: experience at one single Italian center. Journal of Clinical Endocrinology and Metabolism 2020 105.e172-105.e180. (https://doi.org/10.1210/ clinem/dgz113)

Received in final form 4 July 2021

Accepted 14 July 2021

Accepted Manuscript published online 14 July 2021
This work is licensed under a Creative Commons Attribution-NonCommercial 4.0 International License. ded from Bioscientifica.com at 04/26/2023 07:50:59Am 